\title{
Comparison of RegCM3 simulated meteorological parameters in Bangladesh: Part II-preliminary result for temperature
}

\author{
Md. Mizanur Rahman ${ }^{1}$, Md. Nazrul Islam ${ }^{2, *}$, Ahsan Uddin Ahmed ${ }^{3}$ and Romee \\ Afroz $^{1}$ \\ ${ }^{1}$ SAARC Meteorological Research Centre, Dhaka, Bangladesh \\ ${ }^{2}$ Department of Physics, Bangladesh University of Engineering and Technology, Dhaka, Bangladesh \\ ${ }^{3}$ Bangladesh Unnayan Parishad, Niketan, Gulsan 1, Dhaka, Bangladesh
}

\begin{abstract}
Simulation of meteorological parameters and comparison of rainfall for Bangladesh is described in part I. This part II describes the comparison of model simulated temperature for Bangladesh. The parameters are simulated by Regional Climate Model version 3 (RegCM3). Temperature simulated by RegCM3 is compared with surface air temperature collected by the Bangladesh Meteorological Department (BMD) at 29 locations throughout the country. RegCM3 is run at $60 \mathrm{~km} \times 60 \mathrm{~km}$ horizontal grid resolution in a large domain that covers 65$117^{\circ} \mathrm{E}$ and $5-38^{\circ} \mathrm{N}$. Grell scheme with Arakawa-Schubert (GAS) and Fritch-Chappell (GFC) assumptions are used in model simulation. GAS run used Lateral Boundary Conditions (LBCs) data for the years of 1995-2000 whereas GFC run used LBC data for 1991, 1994, 1996 and 1999. It is found that a systematic cold bias is existed in simulating temperature for Bangladesh. The model underestimates about $2^{\circ} \mathrm{C}$ in calculating temperature. In GAS assumption, the model can simulate temperature with about $94 \%$ accuracy to the surface air temperature in annual scale. It is found that the GAS option is better than the GFC in simulating temperature in Bangladesh.
\end{abstract}

\section{INTRODUCTION}

Bangladesh is situated in the tropical belt and it has a warm and humid climate in the summer and a dry and cool weather in the winter. Even though Bangladesh is a small

\footnotetext{
* Corresponding author: mnislam@phy.buet.ac.bd
} 
country with a size of $147340 \mathrm{~km}^{2}$, inter-regional climatic differences in this flat country is not minor. The eastern and northeastern parts of the country are wet whereas the central and western parts are dry [1]. The spatial and temporal distribution of temperature is region dependent. Mainly two seasons are recognized in Bangladesh: a dry winter (December to February) and a humid summer (March to November). According to the wind system and rainfall characteristics, the summer is again sub-divided into three: a) pre-monsoon (March-May), b) monsoon (June-September) and c) post-monsoon (October-November) periods [2]. In general, maximum summer temperatures range between $32^{\circ} \mathrm{C}$ and $38^{\circ} \mathrm{C}$. April is the warmest month in most parts of the country. January is the coldest month, when the average temperature for most parts of the country is about $10^{\circ} \mathrm{C}$. The decrease of temperature during July and August is due to the high precipitation activities from the southwest monsoon. In these months, fraction of cloud coverage increases compared to the other months.

In present days global warming is one of the important topics of discussion due to its impacts on the natural disasters. As a result of global warming, temperature in a particular region is being changed and the natural disasters related to the change of temperature cause socio-economic problems for the human beings. Bangladesh is primarily an agrarian economy. Agriculture is the single largest producing sector of economy since it comprises about $30 \%$ of the country's GDP and employing around $60 \%$ of the total labor force. The performance of this sector has an overwhelming impact on major macroeconomic objectives like employment generation, poverty alleviation, human resource development and food security. Rice, Wheat, Jute, Sugarcane, Potato, Pulses, Tea and Tobacco are the principal crops of the country. Production of these crops are related to the climate especially temperature. Very little research work is done on temperature in and around Bangladesh. Quadir et al. [3] reported the variation of surface air temperature over the land areas in and around the Bay of Bengal. In Bangladesh, the crop sub-sector dominates the agriculture sector contributing about $72 \%$ of total production. Fisheries, livestock and forestry sub-sectors are $10.33 \%, 10.11 \%$ and $7.33 \%$ respectively. However, due to calamities like flood, loss of food and cash crops is a recurring phenomenon, which disrupts the continuing progress of the entire economy. Almost every year Bangladesh is affected by natural disasters such as flood, drought and cyclones. The agriculture sector of any country like Bangladesh is under threat due to the increase of temperature. Temperature affects the crop production as well as water management and infra structure development of the country. Therefore, simulation of temperature for the lead time would 
be benevolent for policy making of the country for national interest. To use the simulated lead time temperature, comparison of the present or base line temperature is one of the important tasks. A regional climate model can be used for the purpose of simulating meteorological parameters like temperature. The regional climate model named RegCM3 (developed by ICTP, Triesty, Italy $[4,5,6]$ ) is the candidate to generate the future temperature in and around Bangladesh. The simulated temperature is to be compared with the ground based surface data before using it. Using the predicted range of temperature it may be possible to formulate future planning for agriculture, water and food management.

\section{DATA USED AND METHOD OF ANALYSIS}

The monthly and seasonal variability of temperature has been studied using the model output and observed data at 29 sites throughout Bangladesh (Fig. 1). The observed surface air temperature was collected by the Bangladesh Meteorological Department (BMD). Two runs were performed by RegCM3: a) using lateral boundary conditions (LBC) data for 4 years (1991, 1994, 1996 and 1999) in Grell scheme with Fritsch-Chappell (GFC) [7]

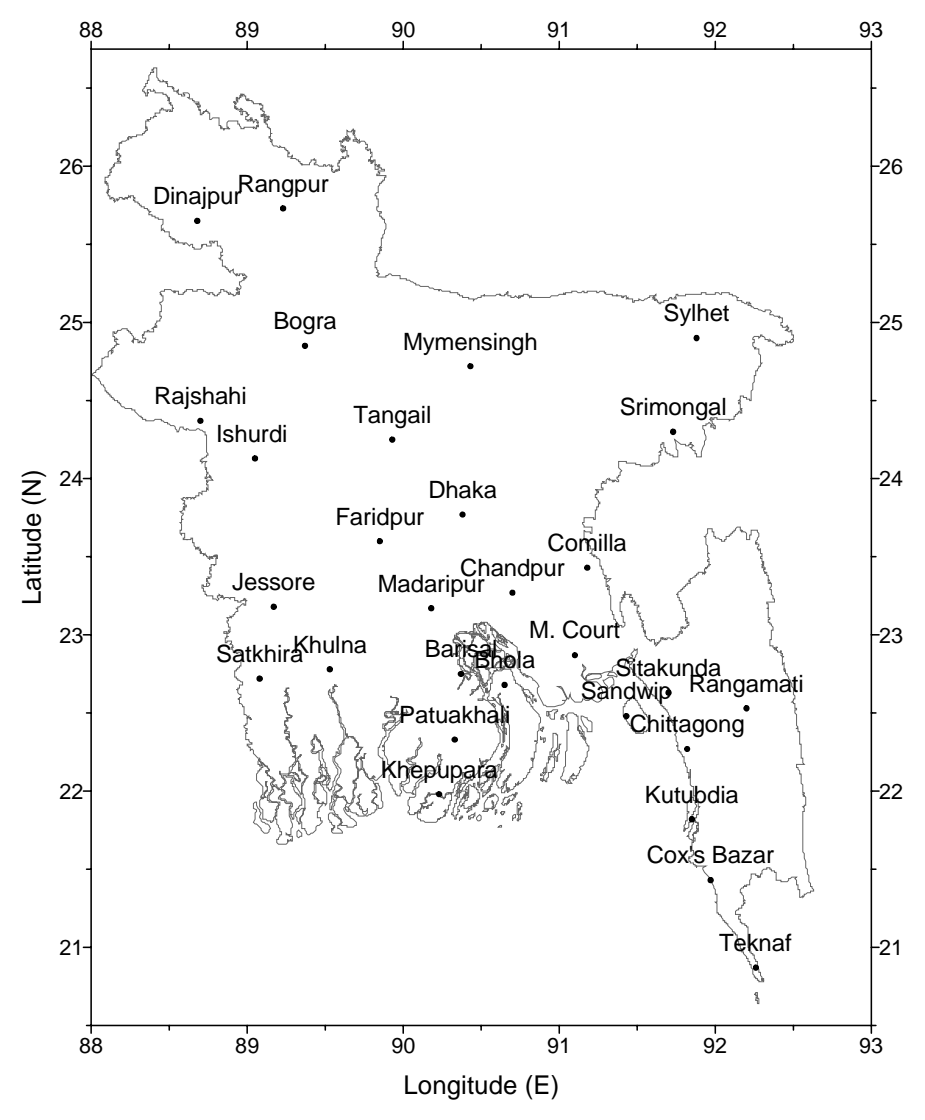

Fig. 1. Temperature measurement locations of Bangladesh Meteorological Department (BMD) throughout the country. 
assumption and b) using LBC data for 7 years (1991 and 1995-2000) in Grell scheme [8, 9] with Arakawa-Schubert (GAS) assumption. The National Centre for Environmental Prediction (NCEP) LBC data are used as the input for the model run. There are two options for Sea Surface Temperature (SST) data can be used as model input. One is the Global Interpolation Sea Surface Temperature (GISST) one-degree monthly gridded data available from the Hadley Centre Met Office. Another is the Optimum Interpolation Sea Surface Temperature (OISST) one-degree weekly analysis available from the National Oceanic and Atmospheric Administration (NOAA). In this analysis OISST is used. Simulated temperature at each observation site is extracted and processed. The BMD collected surface air temperature was compared with RegCM3 simulated temperature in both options of GAS and GFC.

\section{RESULTS AND DISCUSSION}

\subsection{Comparison of observed and model (GAS and GFC) temperature}

Monthly country average temperature (averaged from 29 stations of Bangladesh) for the entire rainy period (March to November) of 1991, 1994, 1996 and 1999 is shown in Fig. 2. For the northwest station Dinajpur (Fig. 2(a)), the simulated temperature in GAS option is found to be closer to observed value compared to the GFC option. In Fig 2(b), the simulated temperature at southern station Khepupara also shows similar patterns of observed values. There is a substantial difference between temperatures of stations Dinajpur and Khepupara. Dinajpur is located inland and in a dry zone whereas Khepupara is located in the coast and in a wet zone [1]. The climatic condition and the gradient of temperature for two stations are different. However, for both stations simulated temperature followed the similar patterns of observed one and GAS option is better than GFC.

Monthly temperature averages for 29 stations in 4 years (1991, 1994, 1996 and 1999) are shown in Fig. 3. It is again seen that GAS option simulates better than GFC option even though both underestimate the temperature. The cold bias (model-observation) for GAS option is found $-3.4,-2.6,-2.1,-1.2,-1.3,-1.2,-1.5,-1.8$ and $-1.8{ }^{\circ} \mathrm{C}$ for March, April, May, June, July, August, September, October and November, respectively. 

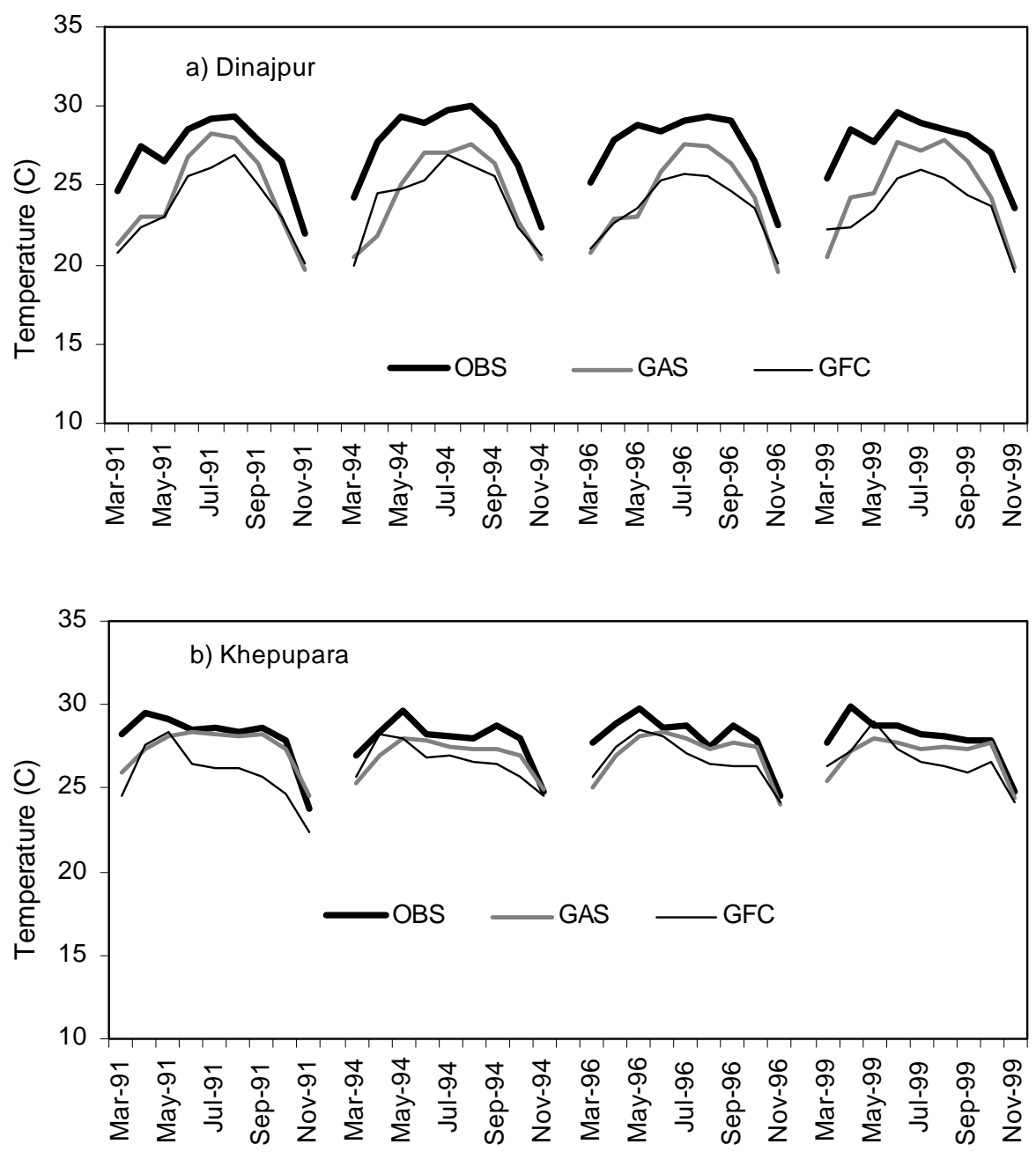

Fig. 2. Monthly average temperature obtained from observation (OBS), model (GAS and GFC) in different months of 1991, 1994, 1996 and 1999 for (a) Dinajpur and (b) Khepupara.

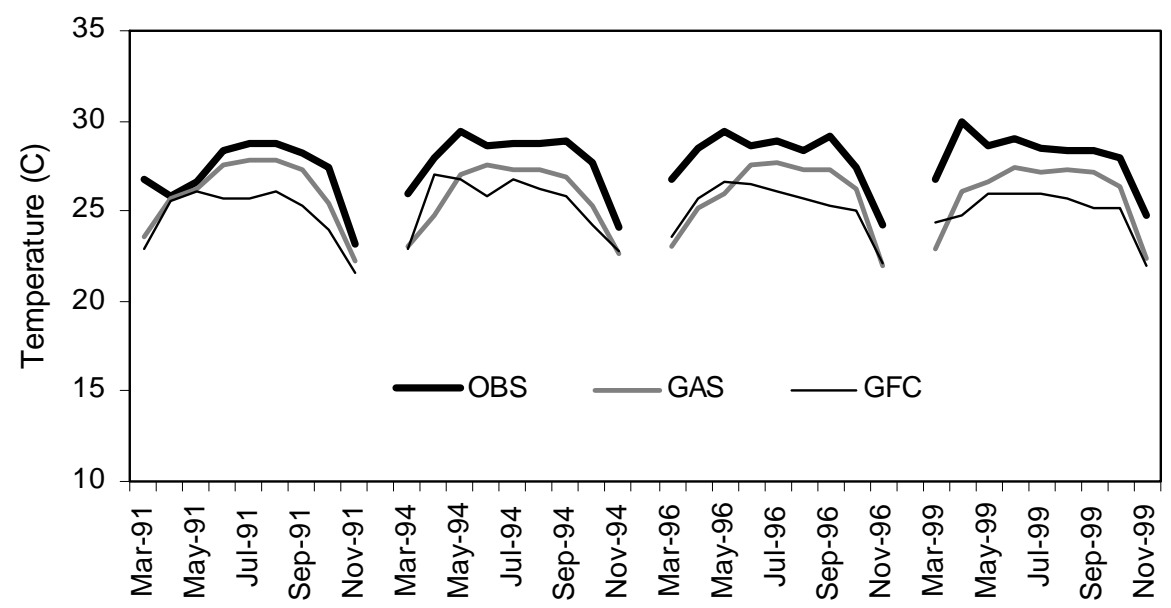

Fig. 3. Same as Fig. 2 except for averages from 29 stations over the country.

Details of the monthly average temperature obtained by observation (Obs) and model (GAS and GFC) with their biases in 1991, 1994, 1996 and 1999 is tabulated in Table 1. It is seen that 
bias is low for monsoon period (June-September) and definitely for GAS option compared to GFC option.

Table1: Country average monthly temperature determined by observation and model (GAS and GFC) for the year 1991, 1994, 1996 and 1999.

\begin{tabular}{|c|c|c|c|c|c|c|c|c|c|c|c|c|c|}
\hline Year & Month & Obs & GAS & GFC & $\begin{array}{l}\text { Obs- } \\
\text { GAS }\end{array}$ & $\begin{array}{l}\text { Obs- } \\
\text { GFC }\end{array}$ & Year & Month & Obs & GAS & GFC & $\begin{array}{l}\text { Obs- } \\
\text { GAS }\end{array}$ & $\begin{array}{l}\text { Obs- } \\
\text { GFC }\end{array}$ \\
\hline \multirow{9}{*}{1991} & Mar & 26.7 & 23.6 & 22.9 & 3.1 & 3.9 & \multirow{9}{*}{1996} & Mar & 26.8 & 23.0 & 23.6 & 3.8 & 3.2 \\
\hline & Apr & 25.8 & 25.7 & 25.6 & 0.1 & 0.2 & & Apr & 28.5 & 25.2 & 25.8 & 3.3 & 2.8 \\
\hline & May & 26.6 & 26.3 & 26.1 & 0.4 & 0.5 & & May & 29.4 & 26.0 & 26.7 & 3.4 & 2.8 \\
\hline & Jun & 28.3 & 27.6 & 25.7 & 0.8 & 2.7 & & Jun & 28.6 & 27.5 & 26.4 & 1.1 & 2.2 \\
\hline & Jul & 28.7 & 27.8 & 25.7 & 0.9 & 3.0 & & Jul & 28.9 & 27.6 & 26.1 & 1.2 & 2.7 \\
\hline & Aug & 28.7 & 27.8 & 26.1 & 0.9 & 2.7 & & Aug & 28.3 & 27.2 & 25.7 & 1.1 & 2.5 \\
\hline & Sep & 28.2 & 27.3 & 25.3 & 0.8 & 2.9 & & Sep & 29.2 & 27.3 & 25.4 & 1.9 & 3.8 \\
\hline & Oct & 27.4 & 25.4 & 23.9 & 2.0 & 3.5 & & Oct & 27.4 & 26.2 & 25.1 & 1.2 & 2.4 \\
\hline & Nov & 23.1 & 22.2 & 21.6 & 1.0 & 1.6 & & Nov & 24.3 & 21.9 & 22.1 & 2.4 & 2.2 \\
\hline \multirow{9}{*}{1994} & Mar & 26.0 & 23.0 & 22.9 & 2.9 & 3.1 & \multirow{9}{*}{1999} & Mar & 26.8 & 22.9 & 24.3 & 3.8 & 2.5 \\
\hline & Apr & 28.0 & 24.8 & 27.0 & 3.2 & 1.0 & & Apr & 29.9 & 26.1 & 24.8 & 3.8 & 5.2 \\
\hline & May & 29.4 & 27.0 & 26.8 & 2.5 & 2.6 & & May & 28.6 & 26.6 & 25.9 & 2.0 & 2.7 \\
\hline & Jun & 28.7 & 27.5 & 25.8 & 1.2 & 2.9 & & Jun & 29.0 & 27.4 & 25.9 & 1.6 & 3.0 \\
\hline & Jul & 28.8 & 27.2 & 26.7 & 1.6 & 2.1 & & Jul & 28.5 & 27.1 & 26.0 & 1.3 & 2.5 \\
\hline & Aug & 28.8 & 27.3 & 26.2 & 1.5 & 2.6 & & Aug & 28.4 & 27.2 & 25.7 & 1.2 & 2.7 \\
\hline & Sep & 28.9 & 26.9 & 25.8 & 1.9 & 3.1 & & Sep & 28.3 & 27.1 & 25.1 & 1.2 & 3.2 \\
\hline & Oct & 27.6 & 25.3 & 24.2 & 2.4 & 3.4 & & Oct & 27.9 & 26.4 & 25.2 & 1.5 & 2.8 \\
\hline & Nov & 24.1 & 22.6 & 22.8 & 1.6 & 1.4 & & Nov & 24.7 & 22.4 & 22.0 & 2.4 & 2.8 \\
\hline
\end{tabular}

We can prepare the adjustment of future temperature from the model outputs using the following equation:

$$
\mathrm{T}_{\text {obs }}=\mathrm{T}_{\text {mod }}+\mathrm{T}_{\mathrm{C}} \quad \text { in }{ }^{\circ} \mathrm{C}
$$

The predicted value of temperature $\left(\mathrm{T}_{\mathrm{obs}}\right)$ can be obtained from the model simulation ( $\left.\mathrm{T}_{\text {mod }}\right)$ after adding a constant $\left(\mathrm{T}_{\mathrm{C}}\right)$ value. The bias information prepared for each station and for long time analysis can help us to find $\mathrm{T}_{\mathrm{C}}$ to adjust the lead time model data for the application purposes. 


\subsection{Comparison of observed and model temperature}

Because the model output of GAS option is found to be much closer to observation, detailed analysis was performed using GAS simulated temperature data for the years 19952000.

Distribution of air temperature over Bangladesh obtained by observation and GAS option for November 1991 is shown in Fig. 4(a) as an example. Temperature is high along the coastal region and gradually decreases towards northwest and lowest values are observed at Dinajpur. A similar situation is observed (Fig. 4(b)) when temperatures averaged for 4 years (1991, 1994, 1996 and 1999). In this case overall temperature increased about 0.22$1.35{ }^{\circ} \mathrm{C}$ for observed data and -0.55 to $1.13^{\circ} \mathrm{C}$ for GAS option. However, for all points the model underestimated except at coastal stations Khepupara and Teknaf.
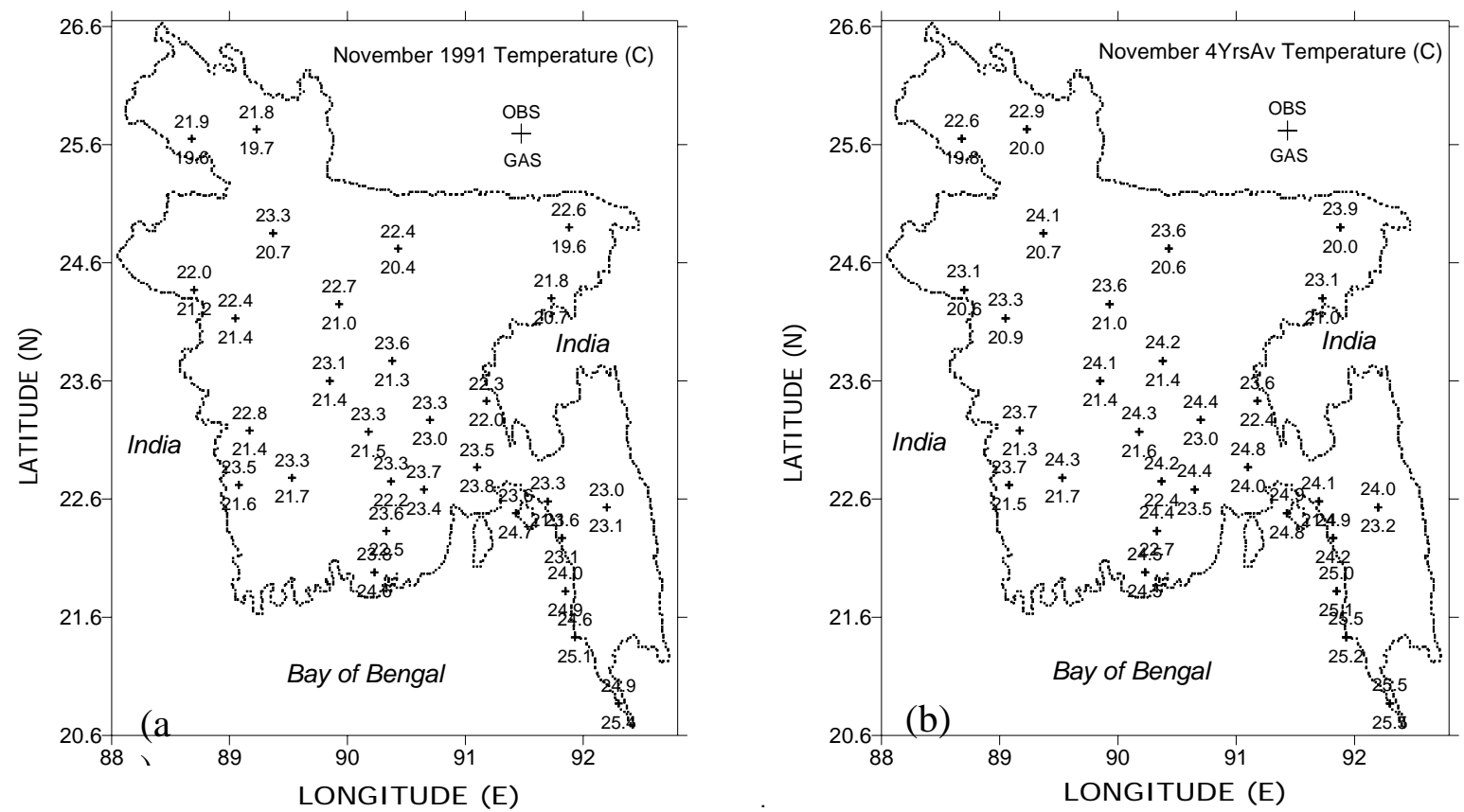

Fig. 4. Spatial distribution of average temperature obtained from observation and GAS (a) November 1991 and (b) averages for November of 4 years (1991, 1994, 1996 and 1999).

Temperatures for all analyzed years (1995-2000) and for all months from January to December at six selected stations named Sylhet, Dinajpur, Dhaka, Satkhira, Khepupara and Teknaf are shown in Fig. 5. These stations were suitably selected from inland (Dinajpur, Sylhet, Dhaka, Satkhira) and coastal (Khepupara and Teknaf). These are also representative of wet (Sylhet, Khepupara and Teknaf) and dry (Dinajpur, Dhaka and Satkhira) regions of the country. It is very clear that the pattern of the change of temperature in different months for all stations is similar: simulated value followed the 
observed one. A systematic cold bias existed for the model simulation (in GAS option). One distinct feature that the magnitude of cold bias decreases from north to south and the bias is very little for the most southeastern station at Teknaf. This is due to the low temperature gradient in the coastal region compared to high gradient inland.
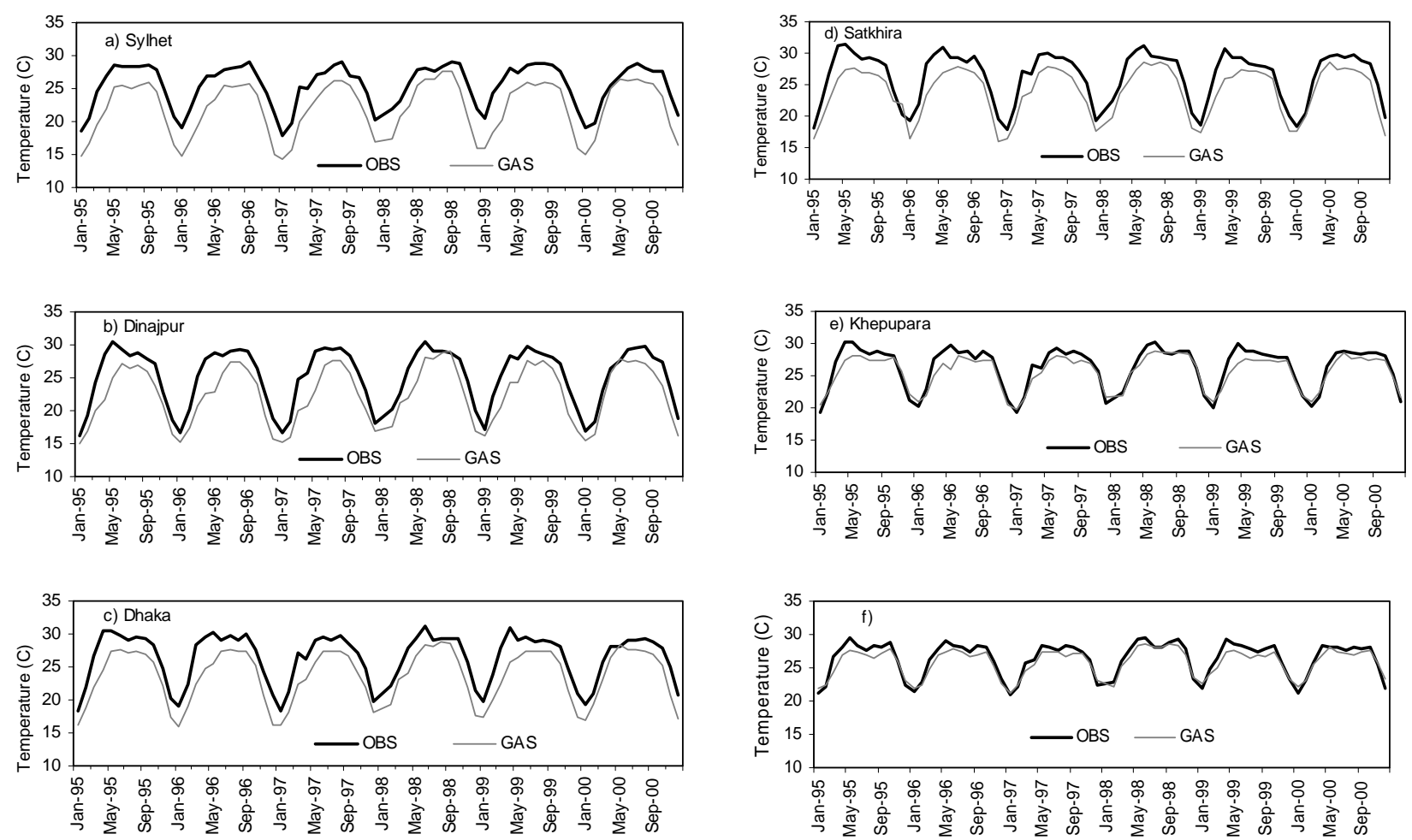

Fig. 5. Time sequences of monthly average temperature obtained from observation and GAS at a) Sylhet, b) Dinajpur, c) Dhaka, d) Satkhira, e) Khepupara and f) Teknaf.

\section{CONCLUSIONS}

In this analysis RegCM3 simulated temperature is compared with surface observation temperature collected by the Bangladesh Meteorological Department from 29 sites throughout Bangladesh for the 6 years 1995-2000. It is found that GAS option simulated surface air temperature has a systematic cold bias of about $2{ }^{\circ} \mathrm{C}$, i.e. if $2{ }^{\circ} \mathrm{C}$ is added to the model data (in GAS option) then it fits with the observed data in Bangladesh. Simulation can detect well the variation of temperature in different parts of the country. Overall, GAS option was found to be better compared to GFC option in simulating temperature in Bangladesh. More work is necessary on other options and other parameters and for long term data analysis. Work on other regional climate models, especially on PRECIS (developed by Hadly Centre, UK) is ongoing to verify the current result before going to 
generate future climatic scenarios. Once all parameters and options in a suitable model are settled, then the generated scenarios can be used for the purpose of forecasting meteorological variables like temperature in Bangladesh.

\section{ACKNOWLEDGEMENTS}

The author wishes to thank the Bangladesh Meteorological Department (BMD) for providing the surface rainfall data. Thanks are due to ICTP, Triesty, Italy and Dr. Kanti Prasad, Head, Theoretical Division, SAARC Meteorological Research Centre (SMRC) for giving the opportunity for preparing the paper. The work is partially supported by the Asia Pacific Network on Global Change Research (APN) and Bangladesh Unnayan Parishad (BUP).

\section{REFERENCES}

1. M. N. Islam, and H. Uyeda, Use of TRMM in determining the climatic characteristics of rainfall over Bangladesh, Remote Sensing of Environment, Elsevier Science (2006)(under review).

2. M. N. Islam, and H. Uyeda, Use of TRMM in determining the climatic characteristics of rainfall over Bangladesh, Remote Sensing of Environment, Elsevier Inc., (2006) doi:10.1016/j.rse.2006.11.011.

3. D. A. Quadir, M. L. Shrestha, T. M. A Khan, N. Ferdoshi, M. Rahman, and A. Mannan, Variation of surface air temperature over the land areas in and around the Bay of Bengal, Natural Hazards, 31, (2004) 561-584.

4. F. Giorgi, M. R. Marinucci, and G.T. Bates, Development of a second generation regional climate model (RegCM2) I: Boundary layer and radiative transfer processes, Monthly Weather Review, vol. 121, (1993) 2794-2813.

5. F. Giorgi, G. Bates, and S. Hostetler, Towards the simulation of the effects of the great lakes on regional climate, Monthly Weather Review, 121, (1993) 1373-1387.

6. F. Giorgi, Simulation of regional climate using a limited area model nested in a general circulation model, Journal of Climate, $\underline{3}(9)$, (1990) 941-963.

7. J. M. Fritsch, and C. F. Chappell, Numerical prediction of convectively driven mesoscale pressure systems. part i: Convective parameterization, Journal of Atmospheric Sciences 37, (1980) 1722-1733.

8. G. Grell, Prognostic evaluation of assumptions used by cumulus parameterizations, Mon. Wea. Rev., 121, (1993) 764-787.

9. G. Grell, Y.-H. Kuo and R. J. Pasch, Semi-prognostic tests of cumulus parameterization schemes in the middle latitudes, Mon. Wea. Rev., 119, (1991) 5-31. 